\title{
SOP 05: Patient Information and Informed Consent
}

\section{Background}

Adequate patient information with particular emphasis on the fact that participation in the study is voluntary is a particular concern of the 'Declaration of Helsinki' [1] and Guidelines on Good Clinical Practice. Great care must therefore be taken in formulating and adapting a written patient information sheet to the particular requirements of a given study. The written patient information must be submitted to the relevant Ethics Committee together with the trial protocol.

\section{Elements of Information to Patients}

There are no regulations specifying the format of the patient information sheet. Information material should be written in layperson's terms.

According to ICH-GCP [2; chapter 4.8.10], both the informed consent discussion and the written informed consent form and any other written information to be provided to subjects should include explanations of the following:

- That the trial involves research.

- The purpose of the trial.

- The trial treatment(s) and the probability for random assignment to each treatment.

- The trial procedures to be followed, including all invasive procedures.

- The subject's responsibilities.

- Those aspects of the trial that are experimental.

- The reasonably foreseeable risks or inconveniences to the subject and, when applicable, to an embryo, fetus, or nursing infant.

- The reasonably expected benefits. When there is no intended clinical benefit to the subject, the subject should be made aware of this.

- The alternative procedure(s) or course(s) of treatment that may be available to the subject, and their important potential benefits and risks.
- The compensation and/or treatment available to the subject in the event of trial-related injury.

- The anticipated prorated payment, if any, to the subject for participating in the trial (comment: commonly not accepted for studies in patients).

- The anticipated expenses, if any, to the subject for participating in the trial.

- That the subject's participation in the trial is voluntary and that the subject may refuse to participate or withdraw from the trial, at any time, without penalty or loss of benefits to which the subject is otherwise entitled.

- That the monitor(s), the auditor(s), the IRB/IEC, and the regulatory authority(ies) will be granted direct access to the subject's original medical records for verification of clinical that procedures and/or data, without violating the confidentiality of the subject, to the extent permitted by the applicable laws and regulations and that, by signing a written informed consent form, the subject or the subject's legally acceptable representative is authorizing such access.

- That records identifying the subject will be kept confidential and, to the extent permitted by the applicable laws and/or regulations, will not be made publicly available. If the results of the trial are published, the subject's identity will remain confidential.

- That the subject or the subject's legally acceptable representative will be informed in a timely manner if information becomes available that may be relevant to the subject's willingness to continue participation in the trial.

- The person(s) to contact for further information regarding the trial and the rights of trial subjects, and whom to contact in the event of trial-related injury.

- The foreseeable circumstances and/or reasons under which the subject's participation in the trial may be terminated.

- The expected duration of the subject's participation in the trial.

- The approximate number of subjects involved in the trial. 
Please note: Ethics Committees commonly require the inclusion of standard text sections, e.g. on mandatory insurance of trial subjects (with local address, policy number, as well as phone and fax numbers of the insurance). Clear and simple definitions of technical terms are mandatory. Since these requirements are not uniform, it may be necessary to prepare alternative versions of the patient information sheet for individual participating centers. In order not to delay the activation of a study, all members of the study group are expected to inform the Coordinating Investigator and sponsor of any such standard elements. It is the responsibility of each participating center to provide the sponsor with a copy of the adapted information sheet together with the approval by the relevant Ethics Committee.

\section{Model Texts}

Attached are model texts for the patient information sheet and the informed consent form. The texts contain the mini- mal elements required for all studies. These have to be supplemented with additional details as needed for a particular study and investigational drug.

\section{References}

1 Der Weltärztebund: Deklaration von Helsinki - Empfehlung für Ärzte, die in der biomedizinischen Forschung am Menschen tätig sind. (revised in Edinburgh, October 2000).

2 ICH-GCP: EMEA. Note for Guidance on Good Clinical Practice (CPMP/ICH/135/95).

\section{Appendix}

Attachment 1: Model Patient Information/Informed Consent (Template for phase II studies; NCI/Bethesda) Attachment 2: Dokumentvorlage für Patienten-Einverständniserklärung (Template for Patient Information/Informed Consent derived from template of the NCI) 

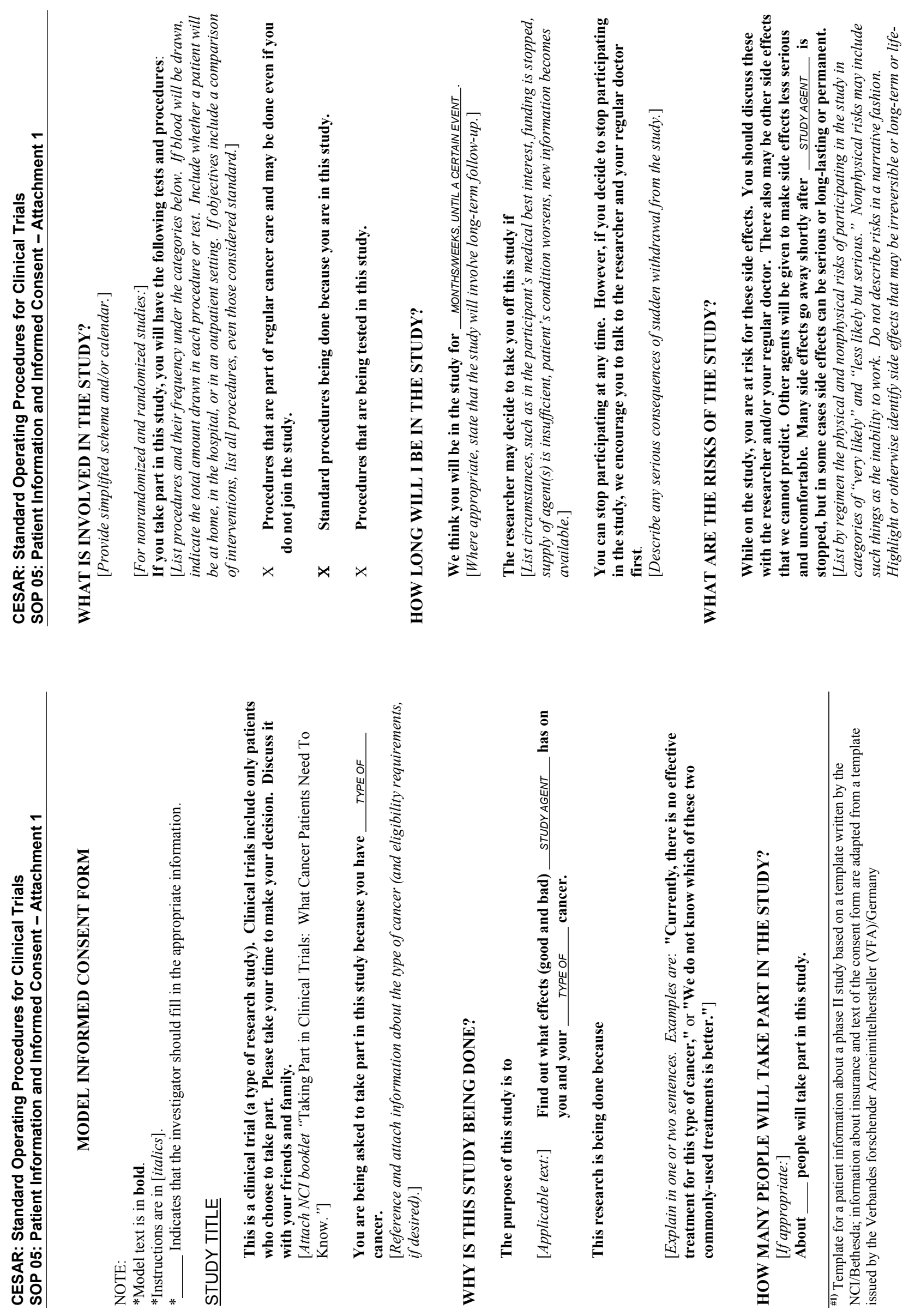

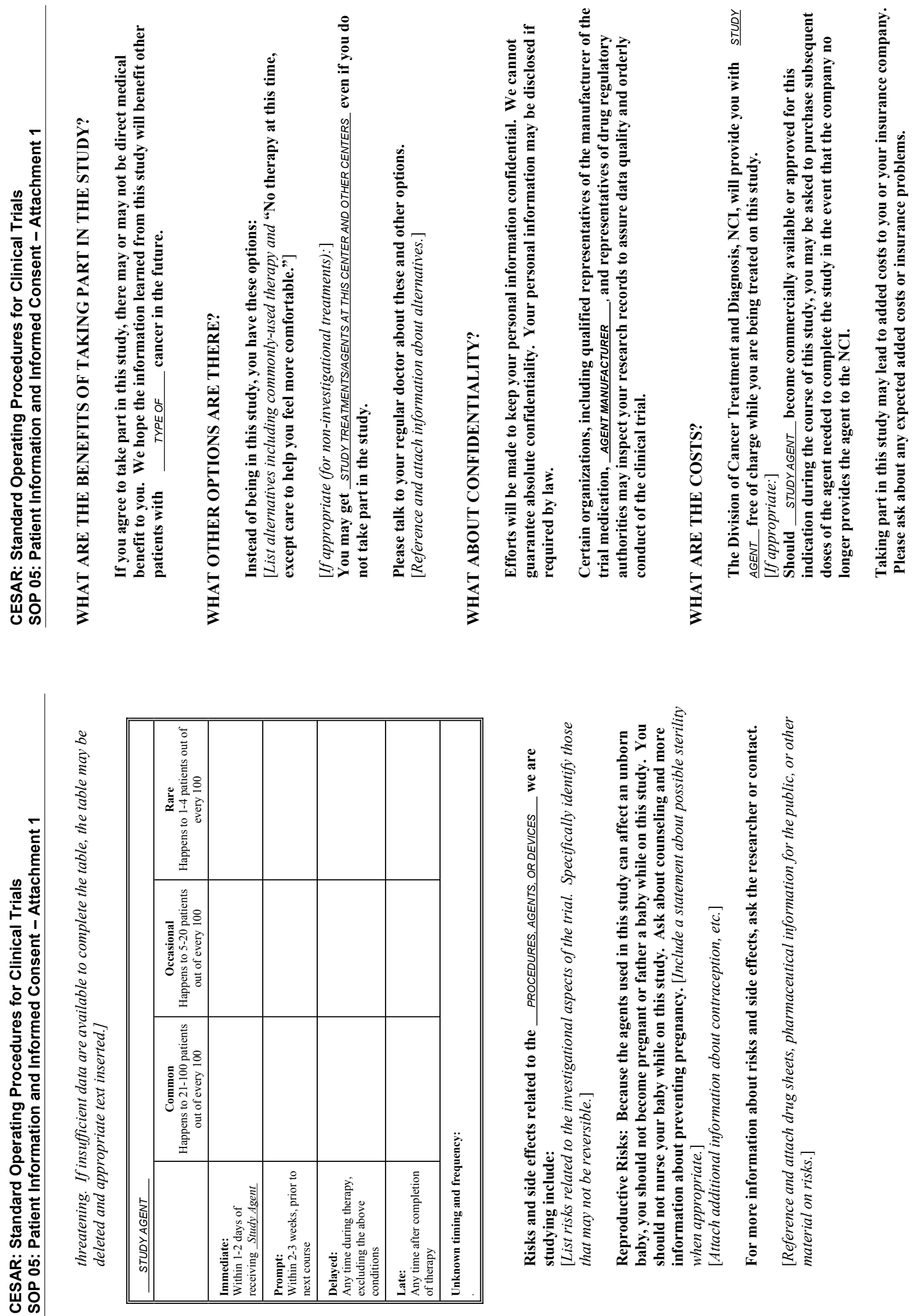

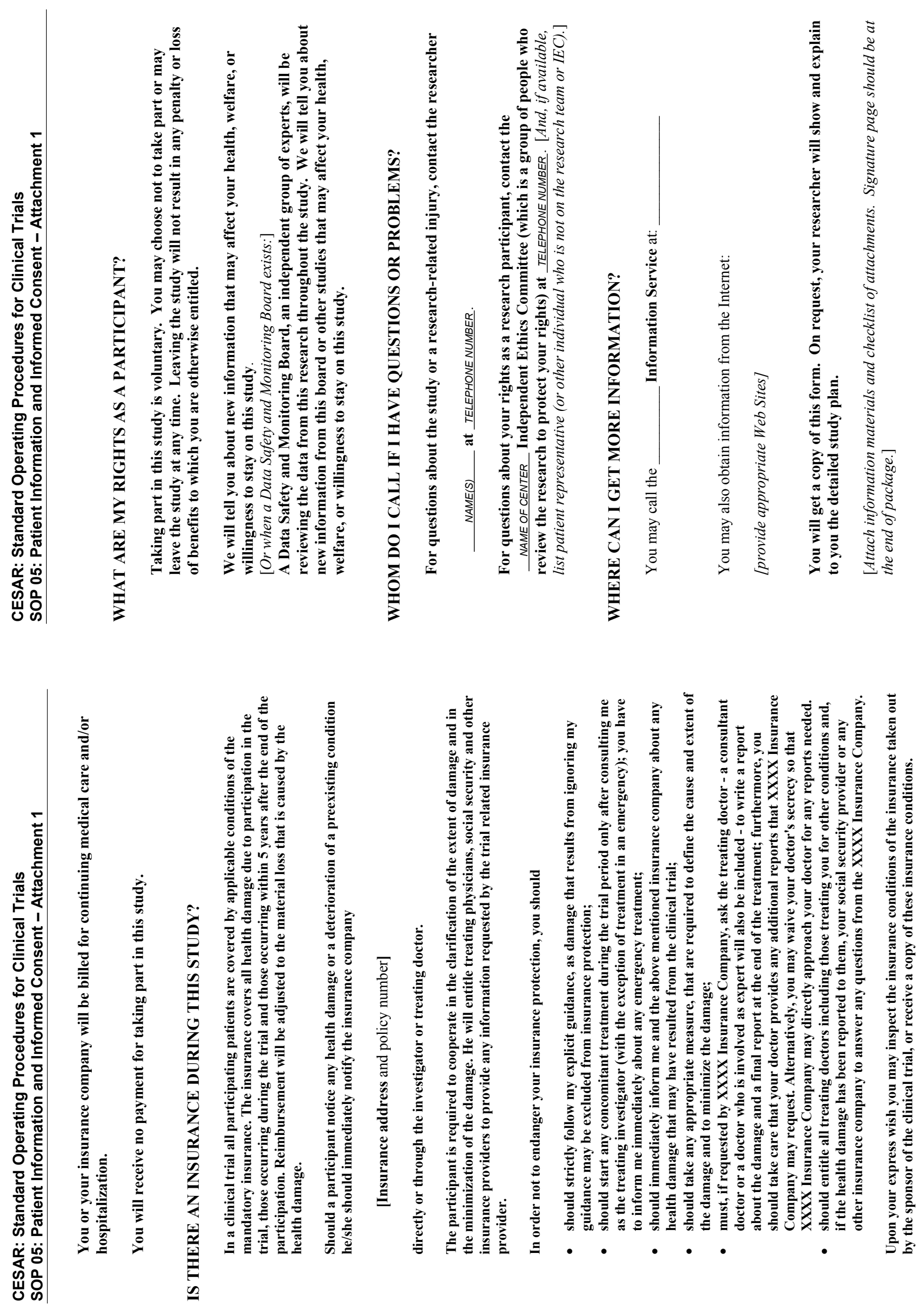

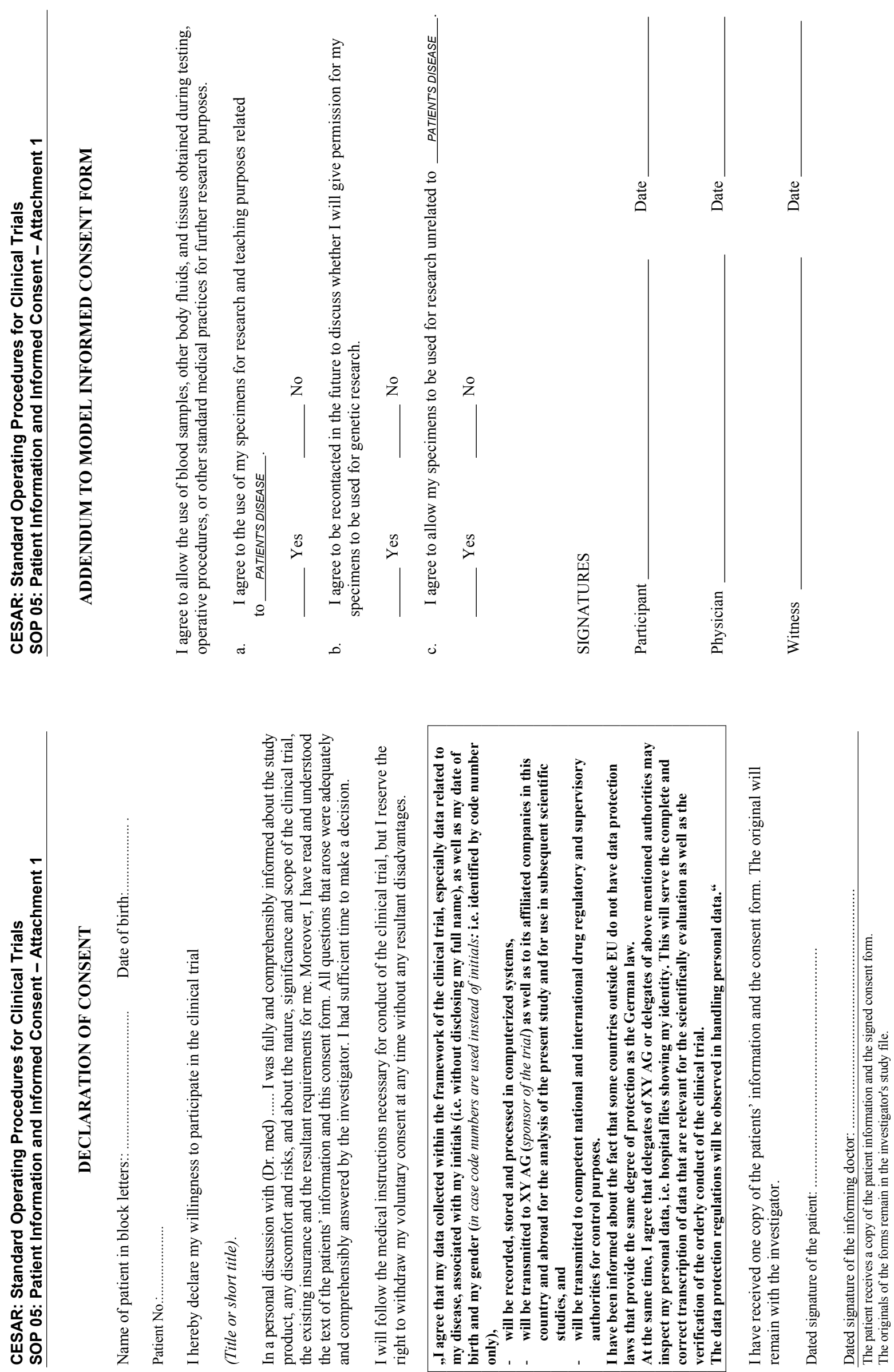

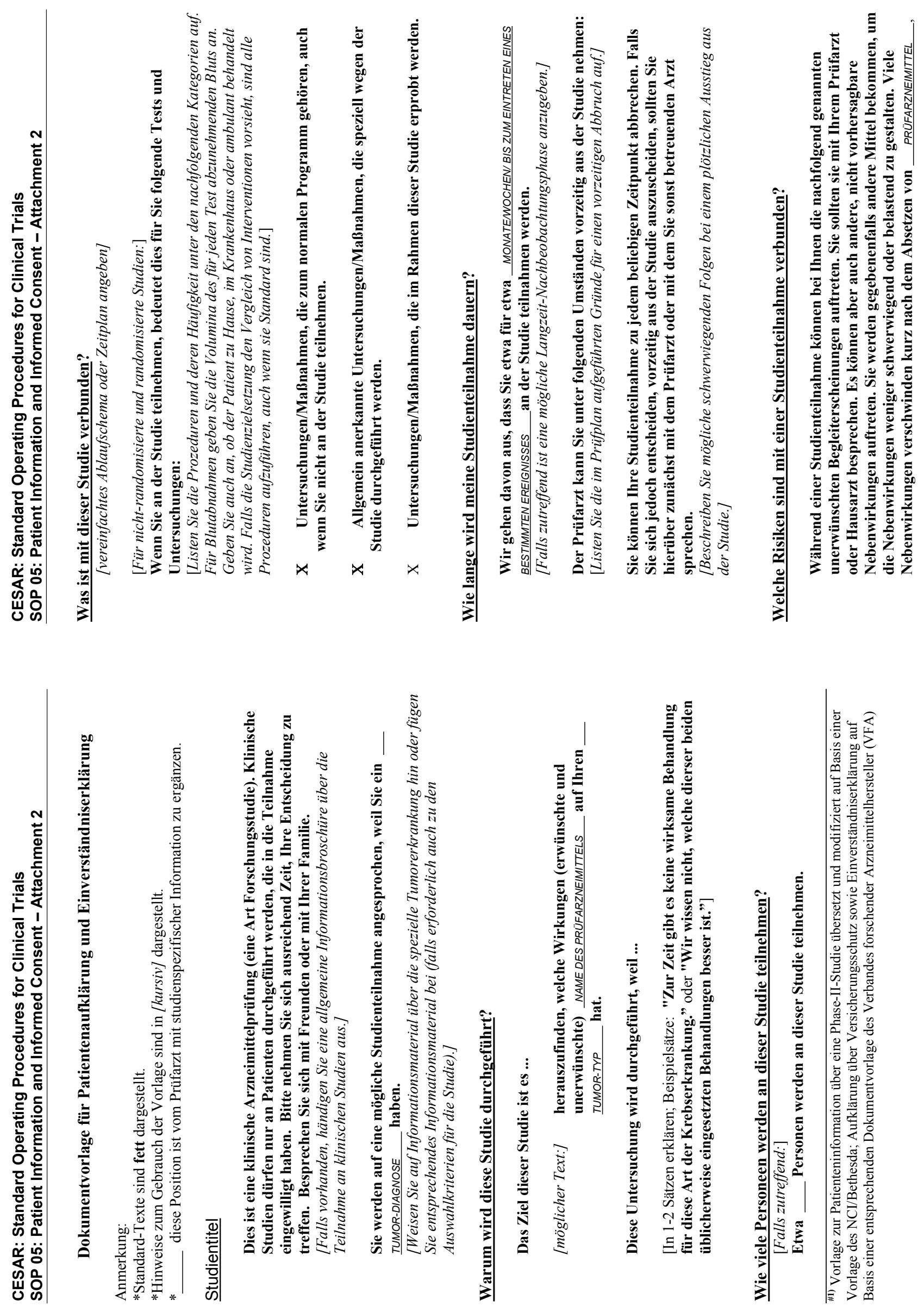

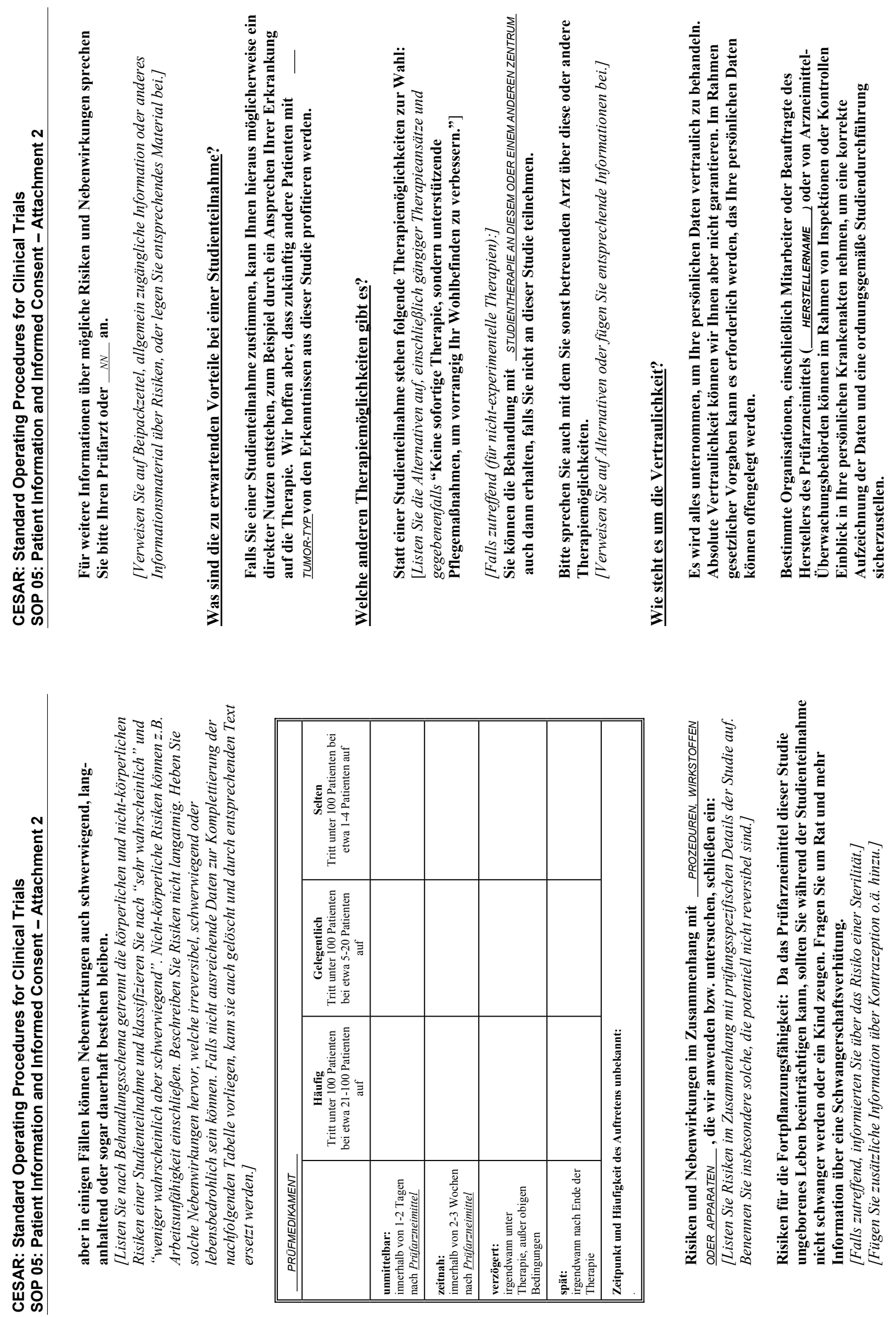

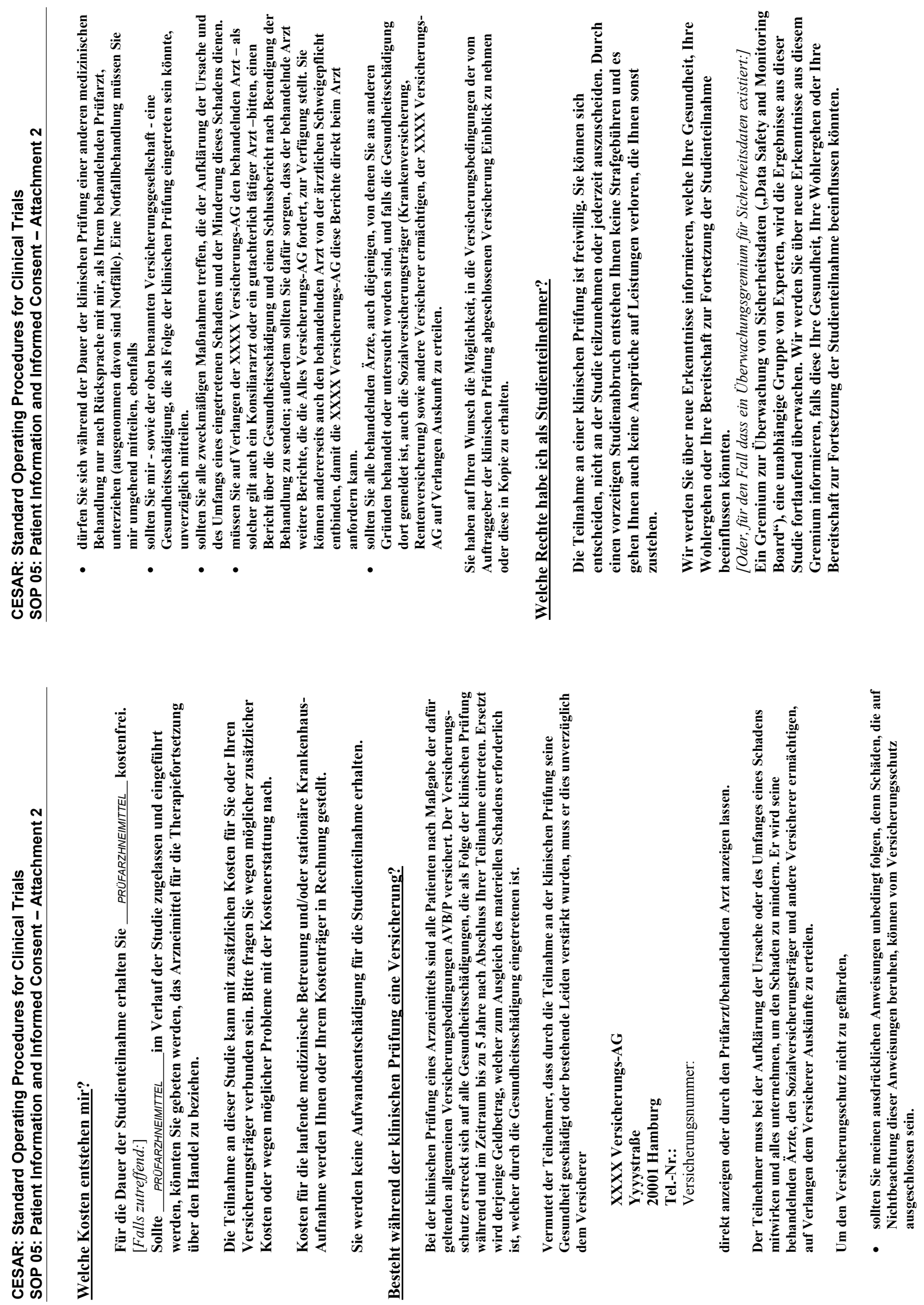

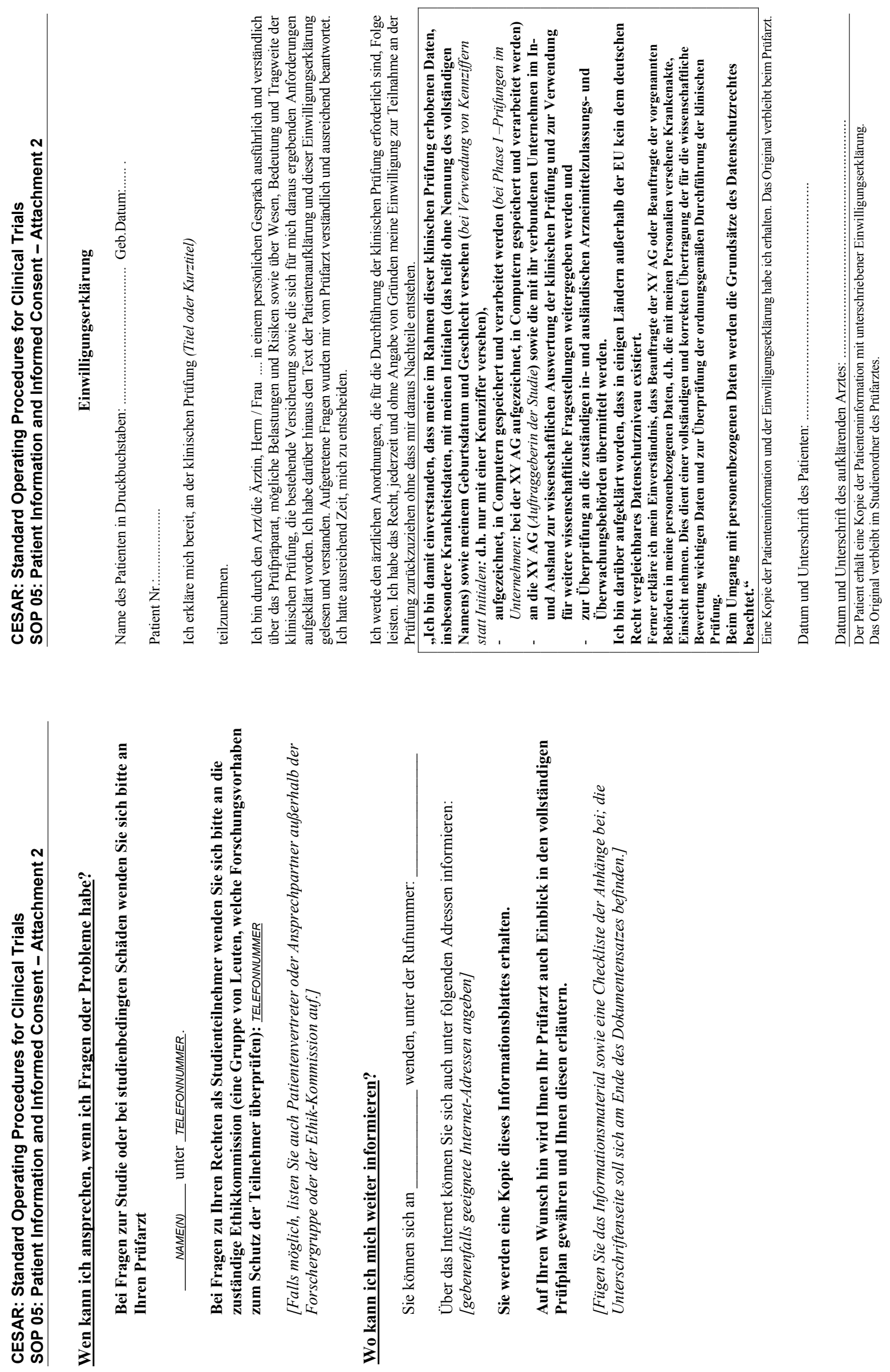

32

Onkologie 2003; 26 (suppl 6): 23-33

Standard Operating Procedures for Clinical Trials of the CESAR Central European Society for Anticancer Drug Research - EWIV 
CESAR: Standard Operating Procedures for Clinical Trials

SOP 05: Patient Information and Informed Consent - Attachment 2

Ergänzung zur Standard-Vorlage der Patientenauf-/Einverständniserklärung

Ich willige ein, dass Blutproben oder andere Körperflüssigkeiten sowie Gewebeproben, die zu diagnostischen Zwecken, bei operativen Maßnahmen oder anderen medizinischen Interventionen im Rahmen der Studie genommen werden, auch für weitere Forschungszwecke verwendet werden.

a. Ich stimme zu, dass die von mir gewonnenen Proben auch zu Forschungs- und Lehrzwecken im Zusammenhang mit_ERKRANKUNG DES PATIENTEN verwendet werden.

$\mathrm{Ja}$

Nein

b. Ich bin bereit, zu gegebener Zeit später darüber zu sprechen, ob ich einer Verwendung meiner Proben für genetische Untersuchungen zustimme. Nein

c. Ich stimme zu, dass die von mir gewonnenen Proben auch zur Forschung über Krankheiten, die nicht im Zusammenhang mit ERKRANKUNG DES PATIENTEN stehen, verwendet werden.

$\mathrm{Ja}$ Nein

\section{Unterschriften}

(Datum und Unterschrift des Patienten)

(Datum und Unterschrift des aufklärenden Arztes)

(Datum und Unterschrift eines Zeugens der Aufklärung) 